Methods A total number of 100 subjects were selected with the age ranging from 45 to 60 years. Among them, 50 diagnosed type 2 diabetes individuals were included in Group A and 50 apparently healthy individuals were selected as Group B for comparison.

Cassia Angustifolia (Senna leaves extract) was prepared in hot water and orally administered to type 2 diabetic patients with constipation. This treatment was thrice a week in the $1^{\text {st }}$ month, twice in a week in corresponding $2^{\text {nd }}$ and $3^{\text {rd }}$ months and once in a week from $4^{\text {th }}$ to $6^{\text {th }}$ months. The defensive enzyme, the glutathione peroxidase, sodium dismutase and catalase were measured in the red blood cells along with the levels of reduced glutathione. The liver function test was performed by measuring hepatic enzymes aminotransferases (Aspartate amino transferase (ASAT) activity, alanine amino transferase (ALAT)) and lipid profile levels.

Results The present study showed that higher levels of serum hepatic enzymes in diabetic patients. The diabetic patients were found to be high blood glucose levels and altered lipid profile with vulnerable to skin infection particularly in the pelvic regions, backside, legs, etc. which were reversed to normal after six months of Senna leaves treatments. The neurological disorder like sustaining pain in legs was also recovered with the treatment. The stools quality also changed to normal. The glutathione peroxidase decreased in red blood cells of diabetics by $20-30 \%$, normalized after six months of treatment with Senna leaves extract. The reduced glutathione found to be decreased in diabetics by $15-20 \%$, normalised. There was also normalize enzymes activity of aminotransferases with treatment to diabetic patients.

Conclusions Senna leaves extract treatment to diabetic patients not only normalize the defense of red blood cells but also corrects skin infection, liver disorder, neurological disorder and physiological disorder.

\section{IDDF2019-ABS-0265 EFFECTS OF DRINKING PLENTY OF WATER FOR BOWEL PREPARATION BEFORE COLONOSCOPY}

Yan Chen*. Guangdong Second Provincial General Hospital Zhuhai High-Tech Zone People's Hospital, China

\subsection{6/gutjnl-2019-IDDFabstracts.216}

Background To investigate the relationship between water quantity and bowel preparation for colonoscopy.

Methods The data of patients undergoing colonoscopy in our hospital between June 1, 2018, and December 31, 2018, were analyzed prospectively. Polyethylene glycol-electrolyte powder and quantity of water were administered in all patients for bowel preparation before colonoscopy. Patients were randomly divided into 3 groups. Group A should drink $3000 \mathrm{ml}$ or more water with the powder, group $\mathrm{C}$ should drink no more than $2000 \mathrm{ml}$, while group B drunk 2000-3000 ml water before colonoscopy. The intestinal cleanliness was evaluated by 3 grades: good (the fluid was transparent and $<5 \%$ of feces was obscured by intestinal contents), moderate (the fluid was a little opaque or $5 \%$ to $10 \%$ of feces was obscured by intestinal contents) and poor (the fluid was opaque or $>10 \%$ of feces was obscured by intestinal contents). The primary measurements included bowel preparation, visualization of intestinal mucosa and patient experience.
Results Bowel preparation with different water quantities was well accepted by subjects and there were no adverse events. The examination takes $10.8 \pm 7.6 \mathrm{~min}(8-20)$. The cleanliness was evaluated as good in group A, B and C were 112 $(88.2 \%), 107(79.9 \%)$ and $72(61.0 \%)$ subjects respectively. The cleanliness was evaluated as poor in group A, B and C were $2(1.6 \%), 10(7.5 \%)$ and $25(21.2 \%)$ subjects respectively. More patients with polyp and other lesions were found in group A than group $\mathrm{B}$ and $\mathrm{C}(\mathrm{P}=0.059)$.

Conclusions Drinking plenty of water has a great impact on bowel preparation. The more water, the more clear vision and easier to detect intestinal lesions.

\section{IDDF2019-ABS-0272 CLINICAL PROFILE OF PATIENTS WITH ACUTE MESENTERIC ISCHEMIA IN NORTHERN INDIA}

Jatin Agrawal* ${ }^{*}$ Anil Arora, Shrihari Anil Anikhindi, Vikas Singla, Praveen Sharma. Institute of Liver, Gastroenterology and Pancreaticobiliary Sciences, Sir Ganga Ram Hospital, New Delhi, India

\subsection{6/gutjnl-2019-IDDFabstracts.217}

Background Acute mesenteric ischemia (AMI) is a medical emergency and constitutes around $0.09-0.2 \%$ of all cases of acute abdomen, with 50\% in-hospital mortality. According to Western literature, AMI most commonly occurs in the $7^{\text {th }}-8^{\text {th }}$ decade, with 50\% mortality, and arterial occlusion being the most common cause. The clinical profile of patients of AMI in India may be different from Western patients; however, the data is lacking. We aimed to study the clinical profile of patients of AMI at a tertiary care centre in northern India.

Methods We retrospectively collected data of consecutive patients of AMI admitted our department from March 2014 to Jan 2019. Data regarding epidemiology, clinical presentation, etiology, imaging, treatment and outcome were studied.

Results Our study included 59 patients (74\% males, median age 52 years). The most common presentation was pain abdomen in $88 \%$, obstipation $40 \%$, gastrointestinal bleeding $17 \%$, and peritonitis $0.5 \%$. Mesenteric Venous thrombosis was seen in $56 \%$, mesenteric artery thrombosis in $30 \%$, mixed thrombosis in $10 \%$ and non-occlusive ischemia in 3\%. Most (71\%) patients required surgical resection. The overall in-hospital mortality was $34 \%$.

Conclusions Unlike the Western literature, the AMI in North India is most commonly due to venous thrombosis, presenting in the sixth decade, and has a lower mortality rate than West. Large prospective studies will be required to elucidate the cause of these differences from Western data.

\section{IDDF2019-ABS-0274 RARE CASE OF GASTRODUODENAL INTUSSUSCEPTION WITH GASTRIC FUNGATING GROWTH, ASCITES AND BOWEL ISCHAEMIA IN AN ELDERLY FEMALE}

Vijsy Sharma*, Richa Sharma. Regional Institute of Health Medicine and Research, Jaipur, Rajasthan, India

\subsection{6/gutjnl-2019-IDDFabstracts. 218}

Background Recently an elderly lady of about 72 years presented to Gastroenterology OPD with pain abdomen, 